\title{
Ecocardiografía avanzada: aplicación clínica actual del análisis de deformación miocárdica y de la imagen tridimensional
}

\section{Advanced echocardiography: current clinical application of the analysis of myocardial deformation and three-dimensional image}

\author{
Juan Francisco Cueva Recalde ${ }^{1,2 *}$, Isaac Lacambra Blasco ${ }^{1}$ \\ ${ }^{1}$ Servicio de Cardiología, Hospital Clínico Universitario Lozano Blesa, Zaragoza, España. \\ ${ }^{2}$ Instituto de Investigación Sanitaria Aragón (IIS Aragón), Zaragoza, España \\ *jfcueva@salud.aragon.es
}

https://doi.org/10.26807/remcb.v38i2.550

Recibido 22-07-2016; Aceptado 20-01-2017

\section{MECÁNICA CARDÍACA: ANÁLISIS DE DE- FORMACIÓN MIOCÁRDICA}

En losúltimos años se ha puesto de manifiesto lanecesidad de trasladar el momento del diagnóstico de las enfermedades cardiovasculares hacia estadios precoces e identificar los pacientes con mínimos cambios estructurales y mayores probabilidades de remodelado inverso. Para hacer realidad este objetivo se necesita un parámetro capaz de detectar los cambios sutiles que se producen en el inicio de la enfermedad.

En la actualidad la determinación de la fracción de eyección del ventrículo izquierdo (FEVI) es el método utilizado para medir la función sistólica, y aunque existe gran cantidad de literatura que respalda esta estrategia, hay varias limitaciones en la práctica diaria; por ejemplo, las técnicas empleadas para calcular la FEVI utilizan fórmulas con asunciones geométricas que no siempre son aplicables y sus resultados son muy susceptibles a cambios en la precarga, asimismo, la frecuencia cardíaca y las alteraciones del ritmo pueden dificultar mucho su interpretación (Marwick 2012). Al hablar de contractilidad regional el escenario se complica aún más. La correcta identificación de asimetrías regionales requiere un proceso de entrenamiento específico, así como la adquisición de experiencia, ya que este análisis es cualitativo, subjetivo y, como toda técnica ecocardiográfica, dependiente de la calidad de imagen disponible.
Por todo esto es que la disponibilidad de una técnica para medir la función sistólica, como el análisis de deformación miocárdica, que sea cuantitativa, reproducible y fiable, supondría un avance considerable en la capacidad diagnóstica de la ecocardiografía actual. Para comprender este enfoque es necesario repasar dos conceptos: la arquitectura del ventrículo izquierdo y la transmuralidad de la enfermedad.

Arquitectura del ventrículo izquierdo.- El conocimiento de la estructura miocárdica del ventrículo izquierdo (VI) es fundamental para comprender el estudio de la deformación, así como para optimizar el análisis de los parámetros de medición (Mor-Avi et al. 2011). Se ha descrito que los miocitos se encuentran dispuestos de manera que forman dos hélices continuas de fibras, pasando de una hélice orientada hacia la derecha en el subendocardio a una hélice orientada hacia la izquierda en el subepicardio, lo que ocasiona que el eje longitudinal de las fibras rote continuamente, y por consiguiente, sea distinto en cada capa de miocardio: longitudinal (respecto al eje del VI) en el subendocardio, circunferencial en el mesocardio y oblicua en el subepicardio (Sengupta et al. 2006). Esta distribución determina como cada región contribuye a la mecánica miocárdica, por ejemplo, la deformación longitudinal se da gracias a las fibras subendocárdicas. El análisis de la deformación de las fibras según su orientación ha permitido definir los patrones de mecánica longitudinal, circunferencial, radial y de torsión (Opdahl et al. 2015). 
Transmuralidad de la enfermedad.- Las fibras longitudinales subendocárdicas son las más vulnerables y también las más sensibles a la presencia de enfermedad, por lo tanto, su valoración permitirá conseguir el objetivo de diagnóstico precoz. Hay que tener en cuenta que la FEVI no se alterará mientras las fibras mesocárdicas y epicárdicas permanezcan sin afectación, ya que las mecánicas circunferencial y de torsión actuarán como mecanismo compensatorio (Duncan et al. 2014). Por lo contrario, cuando el daño miocárdico es transmural se verán afectadas todas las capas de fibras, con disminución de la mecánica longitudinal, pero también de la circunferencial y de torsión, con el consecuente deterioro de la FEVI.

\section{VALORACIÓN DE LA DEFORMACIÓN MIOCARDICA: PARÁMETROS Y DEFINI- CIONES}

A continuación, se detallan los parámetros empleados en el análisis de la mecánica miocárdica (Claus et al. 2015) (Tabla 1).

El "strain" puede medirse como strain natural o strain Lagrangiano; el primero se refiere a la variación en la longitud respecto a un punto de referencia cambiante, según se produce la deformación; mientras que el segundo hace relación a su dimensión original, habitualmente en telediástole. Además, una estructura al deformarse puede ganar o perder longitud, y por convención el acortamiento se registra como negativo, mientras que el estiramiento como positivo.

Como se observa existen múltiples parámetros que pueden obtenerse en el análisis de deformación miocárdica, sin embargo, únicamente el strain longitudinal global (GLS, del inglés global longitudinal strain) (Kalam et al. 2014) y el strain circunferencial global (GCS, del inglés global circumferential strain), en menor medida, son los que cuentan con la mayor evidencia disponible para su uso en la práctica clínica.

Valores de referencia y variabilidad interproveedores.- Se han publicado muchos trabajos describiendo los rangos de normalidad de cada uno de los parámetros de deformación miocárdica, así como muchos puntos de corte que sirven como valor pronóstico en distintas enfermedades. Sin embargo, dado que en la actualidad el GLS ha alcanzado una aceptación importante dentro de la comunidad científica, solo proporcionaremos estos datos.

Pero al contrario de lo que podría esperar, y como

Tabla 1. Parámetros de deformación miocárdica

\begin{tabular}{|c|c|c|}
\hline & Definición & Parámetros \\
\hline \multirow[t]{2}{*}{ Desplazamiento $(\mathrm{cm})$} & $\begin{array}{l}\text { Es la distancia que se ha movido, cierta estructura, en } \\
\text { dos frames (fotogramas). }\end{array}$ & -Desplazamiento longitudinal \\
\hline & & $\begin{array}{l}\text {-Desplazamiento circunferencial. } \\
\text {-Desplazamiento radial. }\end{array}$ \\
\hline Velocidad (cm/s) & Es el desplazamiento en una unidad de tiempo. & $\begin{array}{l}\text {-Velocidad longitudinal. } \\
\text {-Velocidad circunferencial. } \\
\text {-Velocidad radial. }\end{array}$ \\
\hline \multirow[t]{2}{*}{ Strain $(\%)$} & $\begin{array}{l}\text { Cambio en la longitud de una estructura dentro de un } \\
\text { respectivo plano y en relación a su dimensión inicial (en } \\
\text { telediástole). }\end{array}$ & -Strain longitudinal global/regional. \\
\hline & & $\begin{array}{l}\text {-Strain circunferencial global/regional. } \\
\text {-Strain radial global/regional. }\end{array}$ \\
\hline Strain rate $(1 / \mathrm{s})$ & Velocidad de deformación. & $\begin{array}{l}\text {-Strain rate longitudinal global sistólico pico/diastólico } \\
\text { precoz/diastólico tardío. } \\
\text {-Strain rate circunferencial global sistólico pico/diastólico } \\
\text { precoz/diastólico tardío. } \\
\text {-Strain rate radial global sistólico pico/diastólico } \\
\text { precoz/diastólico tardío. }\end{array}$ \\
\hline \multirow[t]{4}{*}{ 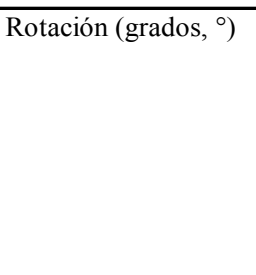 } & $\begin{array}{l}\text { Se refiere a la rotación miocárdica en relación al eje } \\
\text { longitudinal del VI. }\end{array}$ & -Rotación apical sistólica pico. \\
\hline & $\begin{array}{l}\text { El ápex rota en sentido antihorario y la base en sentido } \\
\text { horario (ambos vistos desde el ápex). }\end{array}$ & -Rotación basal sistólica pico. \\
\hline & $\begin{array}{l}\text { El twist se refiere a la diferencia neta de rotación entre } \\
\text { ápex y base. }\end{array}$ & -Twist de VI. \\
\hline & $\begin{array}{l}\text { La torsión es el twist en relación con la longitud del } \\
\text { ventriculo izquierdo. }\end{array}$ & -Torsión de VI. \\
\hline
\end{tabular}


sucede con muchas otras mediciones ecocardiográficas, el GLS no tiene un único punto de corte ni rango de normalidad. Esto se debe a que cada proveedor (empresa desarrolladora del equipo de ecocardiografía y software de análisis) ha desarrollado un algoritmo de procesamiento de datos diferente (Farsalinos et al. 2015, Lang et al. 2015) (Tabla 2).

Tabla 2. Valores de referencia para GLS según distintos proveedores

\begin{tabular}{llcc}
\hline Proveedor & Software & Promedio & LBN \\
\hline GE & EchoPAC BT 12 & $-21,50 \%$ & $-18 \%$ \\
Philips & QLAB 7.1 & $-18,90 \%$ & $-14 \%$ \\
Toshiba & Ultra Extend & $-19,90 \%$ & $-15 \%$ \\
Siemens & VVI & $-19,80 \%$ & $-11 \%$ \\
Esaote & Mylab 50 & $-19,50 \%$ & $-13 \%$ \\
\hline
\end{tabular}

Recientemente se ha publicado un trabajo en el que Farsalinos et al. (2015)., dentro de la iniciativa EACVI/ASE Inter-Vendor Comparison Study, han comparado los valores de GLS obtenidos en 62 pacientes sanos en 9 equpos disponibles en el mercado. Los resultados difirieron en $3 \%$ en el GLS, mientras que la variabilidad intra e interobservador fueron menores que las reportadas para otros parámetros como la FEVI.

\section{TÉCNICAS}

Imagen de Doppler Tisular / Doppler Tissue Imaging (TDI).- La técnica de TDI se base en los mismos principios que el Doppler pulsado y el Doppler color, con la diferencia que se aplican filtros de paso bajos para adaptarse a la menor velocidad que alcanza el tejido (miocardio). El objetivo es el de seguir el movimiento tisular. El TDI color calcula de manera primaria el strain rate (SR) relacionando el gradiente de velocidad y el cambio de longitud, a partir de aquí el strain se determina como una integral.

Para la adquisición de imágenes de DTI se deben tomar en cuenta ciertos aspectos. Se recomienda una alta tasa de fotogramas/segundo (frame rate) $>$ 100 frames/seg; esto se debe acompañar de ajustes con reducción de la profundidad y anchura del sector. Posteriormente se ajusta la escala de velocidad para evitar aliasing en cualquier zona del miocardio. Se guardan bucles de al menos 3 latidos. Todas las imágenes deben tener un FC similar.
Pese a lo anterior, la mayor limitación del TDI es la dependencia del ángulo de incidencia del ultrasonido, cual debe estar paralelo a la región de interés. Se ha recomendado que este ángulo no sea mayor a $15^{\circ}$. Esto hace que la adquisición de la imagen en cada plano sea fundamental.

Se requiere análisis desde diferentes ventanas ecocardiográficas. Es así como desde los planos apicales se registrará la deformación longitudinal, mientras que desde el eje corto paraesternal los planos radial y circunferencial.

Una vez que se han adquirido las imágenes existe la posibilidad de analizarlas offline, este paso es lo que se conoce como posprocesamiento. A partir de la imagen original se obtienen distintos gráficos y curvas que permiten analizar los diferentes vectores de deformación.

Existen otros parámetros que afectan al TDI. El componente de movimiento de traslación del corazón no se puede eliminar. Finalmente, las curvas de strain y SR derivadas de TDI color requieren mayor entrenamiento para su interpretación.

Speckle-Tracking.- Esta tecnología inició su desarrollo hace 10 años aproximadamente. El término speckle-tracking (ST) se refiere al "seguimiento de mota, mancha o partícula". En la escala de grises que conforman la imagen de ultrasonido, se observan numerosas speckles creadas por la interacción del haz de ultrasonido con estructuras de menor tamaño que la longitud de onda utilizada. Tras eliminar señales de ruidos, el software es capaz de seguir bloques de speckles de frame a frame (de manera simultánea en varias zonas de la imagen), proporcionando información de desplazamiento, velocidad y strain; el SR se calcula. En contraste con lo que sucede con la imagen de DTI, el ST permite el análisis de strain y SR en cualquier plano dentro de la imagen. Adicionalmente se puede estudiar de forma separada el endocardio, mesocardio o epicardio.

Para la adquisición de imágenes se requiere un fra$m e$ rate de entre 40-80 frames/seg. Se debe prestar la máxima atención para incluir en el plano todas las paredes del ventrículo izquierdo, principalmente el ápex. Posteriormente el análisis se realiza offline, el primer paso es el de definir el endocardio, esto puede hacerse manualmente o de forma automática. La zona de análisis debe abarcar todo el miocardio y dejar fuera el pericardio. A continuación, se observa si el tracking o seguimiento de los puntos señalados es bueno durante todo el ciclo cardíaco. Si 
aceptamos el tracking, obtendremos los valores de strain deseados (pico, pico en telesístole, etc.) en el plano analizado.

El tiempo en el que medimos el strain también puede variar, el software usa como referencia el cierre de la válvula aórtica, por lo que se deben evitar excesivas variaciones en la FC para obtener un intervalo R-R constante. Para obtener el GLS debemos obtener el strain longitudinal de todos los segmentos miocárdicos, analizando las caras anterolateral e inferoseptal en el plano de $4 \mathrm{C}$, las caras anterior e inferior en el plano de $2 \mathrm{C}$ y las caras inferolateral $\mathrm{y}$ anteroseptal en el plano de 3C (Figura 1). Esta información se obtiene en datos numéricos, pero es de gran utilidad representarla en un esquema de ojo de buey (bull's eye), el cual permite visualizar las

\section{APLICACIONES DEL ANÁLISIS DE DEFOR- MACIÓN MIOCÁRDICA}

Insuficiencia cardíaca con FEVI deprimida.- La utilidad del análisis de deformación miocárdica en los pacientes con IC con FEVI reducida (ICFEr) se ha estudiado desde hace varios años. Stanton et.al., compararon el factor pronóstico de la FEVI, el puntaje de movilidad miocárdica (WMSI, del inglés wall motion score index) y el valor de GLS medido por ST; tras analizar 546 pacientes concluyeron que el GLS tiene una capacidad predictiva superior, para mortalidad total, que FEVI y WMSI (Stanton et al. 2009). Posteriormente, en un trabajo con 125 pacientes sintomáticos con IC, Nahum et.al. (2010), obtuvieron resultados similares al comprobar que únicamente el GLS por ST conservaba su valor

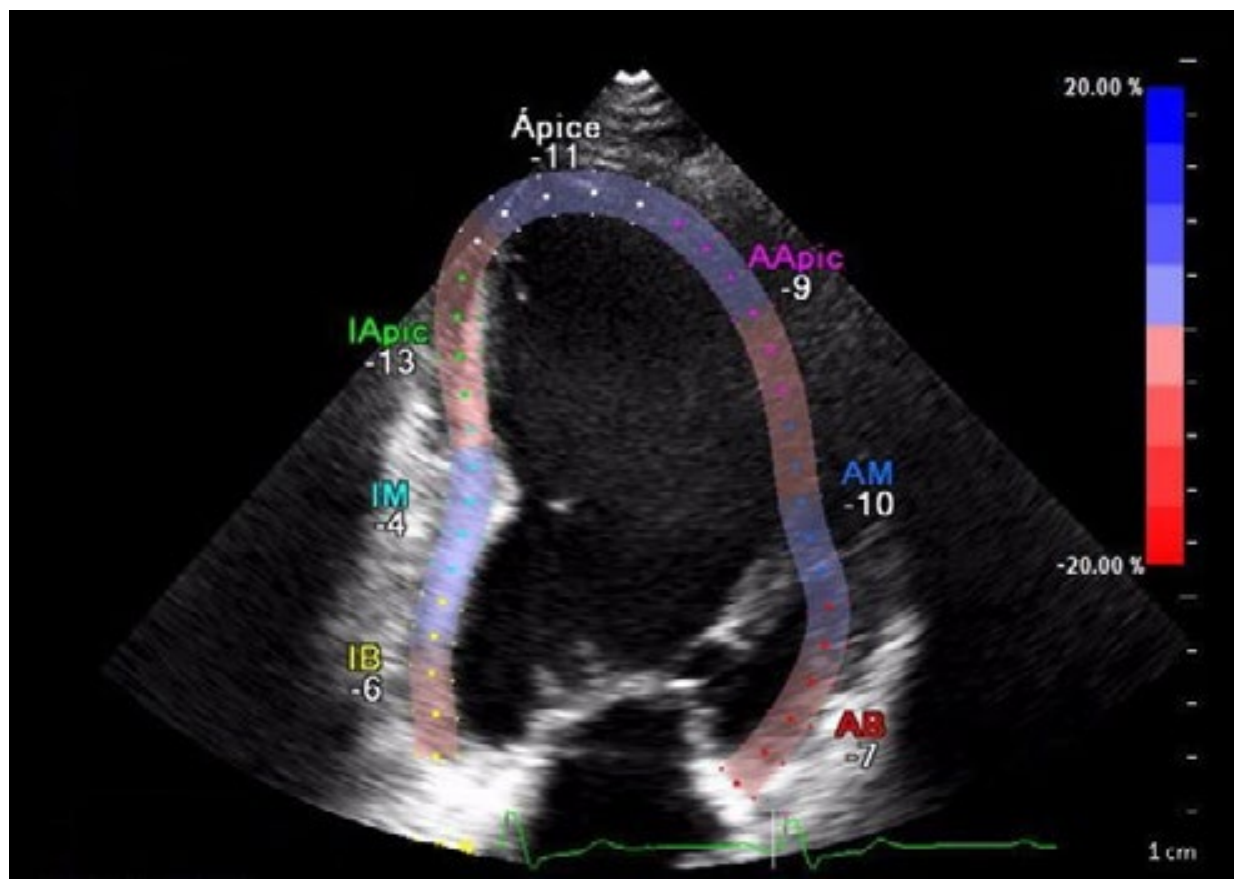

Figura 1. Análisis de strain mediante speckle-tracking. Imagen apical de 2 cavidades, en el que se muestran las caras anterior e inferior del ventrículo izquierdo, cada una con sus segmentos basal, medio y apical (AB, AM, AA, IB, IM e IA). Las cifras reflejan el valor de strain longitudinal de cada región. Estos valores se codifican según la escala de colores.

zonas afectadas de mejor manera (Figura 2).

La principal limitación del ST es el seguimiento inadecuado, el cual está en estrecha relación con la calidad de la imagen. De igual manera, y debido a la dependencia del ST de una alta resolución espacial, su capacidad de análisis será menor en pacientes con taquicardia; escenario en el cual el DTI es mejor. predictivo para eventos cardíacos adversos, tras el análisis multivariable. De forma más reciente, Motoki et.al., encontraron relación entre GLS por ST y disfunción diastólica de VI y disfunción sistólica y diastólica de ventrículo derecho (VD); al igual que los estudios previos, el valor predictivo del GLS para eventos adversos mayores se mantuvo tras el análisis multivariable (Motoki et al. 2012). 


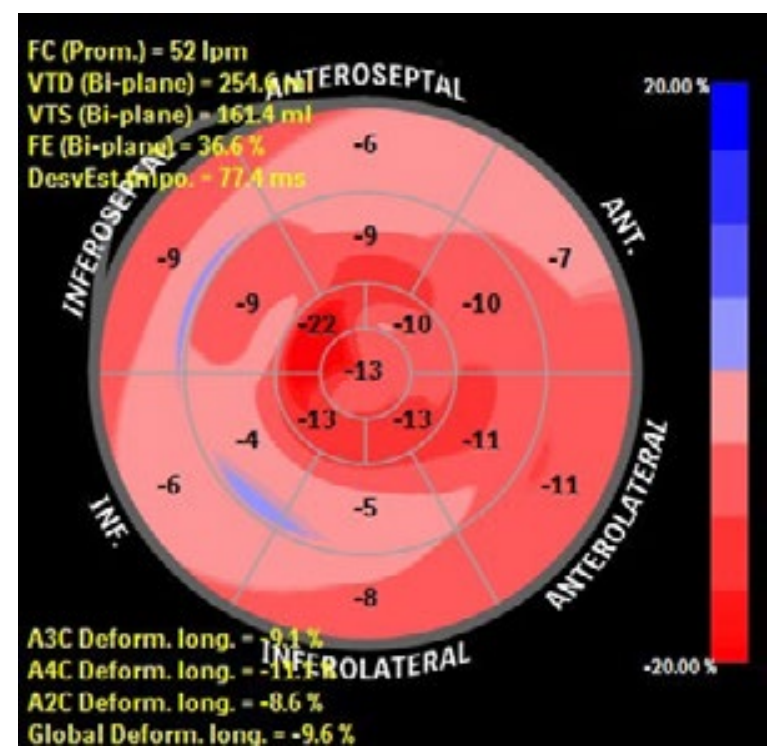

Figura 2. Análisis de strain mediante speckle-tracking, esquema de bull's eye. Se representan todos los segmentos del miocardio y se muestran los valores de strain longitudinal, tanto numéricamente como con escala de colores. En amarillo se proporcionan los datos de strain/deformidad longitudinal en cada imagen apical de 4, 2 y 3 cavidades, y el cálculo automático del GLS. Adicionalmente se observan los datos del cálculo de las dimensiones y función del ventrículo izquierdo por el método biplano (VTD: volumen telediastólico, VTS: volumen telesistólico, FE: fracción de eyección, FC: frecuencia cardiaca).

Hace pocos meses se han publicado los resultados del trabajo con mayor número de pacientes que se ha realizado hasta el momento en lo referente a pacientes con ICFEr y GLS. Sengelov et.al. han estudiado a 1065 pacientes (FEVI $<45 \%$ ) durante 40 meses, tras los cuales concluyen que el GSL es un factor predictor de mortalidad por todas las causas, especialmente en hombres sin fibrilación auricular; esto tras ajustar por muchas y distintas variables demográficas y clínicas (Sengelov et al. 2015).

Insuficiencia cardíaca con FEVI preservada.- En los últimos años se han publicado varios trabajos con resultados negativos en el campo del tratamiento de la insuficiencia cardíaca con FEVI preservada (ICFEp), lo que demuestra el escenario tan complejo de esta patología. En lo referente al diagnóstico y pronóstico no existen muchas diferencias. En un subanálisis del estudio PARAMOUNT con 219 pacientes se demostró que los pacientes con ICFEp muestran valores reducidos de strain longitudinal y strain circunferencial (Kraigher-krainer et al. 2014).

Pero ha sido en este último año en el que se ha conocido el estudio con "mejores" resultados en este tema, el estudio TOPCAT; y este se ha trasladado también al campo del pronóstico. Shah et.al., determinaron el strain longitudinal (en 4C y 2C, no GLS) en 447 pacientes de este estudio y los siguieron du- rante 2,6 años. E1 15,8 \% presentaron alteraciones en los valores de strain, y este fue el principal y más potente predictor del objetivo primario compuesto (mortalidad cardiovascular, hospitalización por IC y parada cardiorrespiratoria recuperada). Al combinar strain con otros parámetros como masa de VI y relación $\mathrm{E} / \mathrm{e}^{\prime}$ se logró identificar a los pacientes con peor pronóstico. Adicionalmente hubo una tendencia a la mejoría de las cifras de strain tras el tratamiento con espironolactona (Shah et al. 2015).

Cardiopatía isquémica.- El ecocardiograma es una herramienta fundamental durante toda la historia natural de la enfermedad coronaria, tanto en la fase aguda sirviendo como apoyo diagnóstico y detectando complicaciones, como en la fase crónica definiendo las consecuencias del evento isquémico para determinar pronóstico, implementar el mejor tratamiento posible y decidir la indicación de revascularización (Mada et al. 2014).

Pese a proporcionar tanta información, el análisis de las alteraciones segmentarias continúa siendo subjetivo, basándose en una habilidad que demanda mucho entrenamiento, destreza y experiencia; es sin duda una de las competencias más difícil de adquirir. En este escenario los parámetros de deformación miocárdica pueden representar una alternativa objetiva y cuantificable. 
La isquemia produce diferencias regionales en la función miocárdica, específicamente reduce la amplitud de la deformación y retrasa el inicio de la activación (produciéndose tras el cierre de la válvula aórtica). Es por esto que el parámetro más útil es el "acortamiento postsistólico".

Técnicamente se compara el strain pico sistólico (antes del cierre de la válvula aórtica) con el strain postsistólico (al menos $90 \mathrm{mseg}$ después del cierre de la válvula aórtica), se considera patológico cuando este último representa $>20 \%$ del primero (Asanuma y Nakatani 2015). Para el estudio basal se pueden emplear tanto ST como TDI; sin embargo, para pruebas de inducción de isquemia es mejor la imagen por TDI debido a su mayor resolución temporal.

Valvulopatías.- En el ámbito de las enfermedades valvulares, la valoración de la función sistólica es de mucha importancia, las guías de práctica clínica vigentes recomiendan sustitución valvular en función de los síntomas y de valores de FEVI, con las limitaciones que puede tener este método. Es por eso que el uso del strain puede suponer un avance hacia el diagnóstico precoz, ya que su variación con los cambios de precarga y poscarga es menor (Galli et al. 2014).

Insuficiencia mitral.- En los pacientes con insuficiencia mitral (IM) primaria, las guías europeas recomiendan cirugía en pacientes asintomáticos con FEVI $<60 \%$ o con diámetro telesistólico de VI $>$ $45 \mathrm{~mm}$ (Vahanian et al. 2012). La FEVI es un predictor potente de disfunción sistólica posquirúrgica con la consiguiente morbimortalidad, sin embargo, existen casos de deterioro severo de la FEVI en pacientes con valores prequirúrgicos normales. Esto último es más preocupante cuando sabemos que la FEVI se suele sobrestimar en pacientes con IM.

De lo anterior podemos intuir la importancia de la detección de disfunción miocárdica subclínica, y solo de esta manera se remitirá a los pacientes al tratamiento quirúrgico de manera oportuna; caso contrario se estarán sometiendo a procedimientos de riesgo que probablemente tengan un beneficio potencial limitado.

Lancellotti et.al. (2008) demostraron que el GLS basal y en pico de ejercicio fueron predictores de FEVI $<50 \%$ en el posquirúrgico. El umbral pronóstico fue un valor de GLS basal de $-18 \%$. Adicionalmente, Magne et.al. (2014) estudiaron a 115 pacientes con IM al menos moderada sin disfunción sistólica, con ecocardiograma de esfuerzo midiendo los cambios en FEVI y GLS. Un aumento de $4 \%$ en el valor de la FEVI no modificó el pronóstico de los pacientes, al contrario de lo que sucedió con el incremento de $2 \%$ en el GLS, los pacientes sin reserva contráctil por cualquiera de los dos métodos presentaron el doble de eventos cardíacos. Esta discrepancia se explica por la dependencia de la FEVI con las condiciones de carga, que a su vez se relaciona por el cambio en la severidad de la IM durante el esfuerzo. Se han propuesto algoritmos diagnósticos y de pronóstico que incluyen ya al GLS (Galli et al. 2014).

Estenosis aórtica.- Al igual que en la IM, las guías europeas recomiendan cirugía en los pacientes con estenosis aórtica (EA) severa y FEVI $<50 \%$ (Vahanian et al. 2012). Lafitte et.al. estudiaron a 65 pacientes asintomáticos con EA severa demostrando que estos presentaban valores más bajos de GLS respecto a los controles, la diferencia es más pronunciada en los segmentos basales (Lafitte et al. 2009). Tal vez el estudio de Weidemann et.al., sea el que ponga más de manifiesto la utilidad del strain, estos autores estudiaron a 58 pacientes con EA severa sintomática sin otras cardiopatías concomitantes, les realizaron ecocardiograma y resonancia magnética cardíaca (RMC) antes de la cirugía determinando el strain longitudinal y el realce tardío de gadolinio como marcador de fibrosis. Durante la cirugía se tomaron biopsias para cuantificar la fibrosis de forma histológica. Tras 9 meses se repitió la RMC y se comprobó que aquellos pacientes con mayor grado de fibrosis en la biopsia no mostraron remodelado inverso (con desaparición del realce tardío) en comparación con aquellos con menos cambios histológicos, quienes además mostraron mejoría en la clase funcional. El strain longitudinal fue el único parámetro capaz de diferenciar a los pacientes que tendrían peor pronóstico (Weidemann et al. 2009).

Cardiotoxicidad.- La disfunción cardíaca secundaria a la administración de antraciclinas se conoce desde los años 1960 cuando se introdujo este fármaco en el tratamiento de las enfermedades neoplásicas (Plana et al. 2014, Thavendiranathan et al. 2014). Los efectos adversos de estos medicamentos pueden producirse según uno de los siguientes patrones: Tipo 1: la forma típica de presentación de las antraciclinas (doxorrubicina), es dosis dependiente y genera apoptosis en los miocitos, es irreversible; y Tipo 2: típico del trastuzumab, no se relaciona con la dosis, no induce apoptosis por lo que es reversible tras la interrupción del fármaco. 
Actualmente se define la cardiotoxicidad en términos de cambios en FEVI con un descenso mayor al $10 \%$ de su valor basal siendo menor de $53 \%$ (Plana et al. 2014, Thavendiranathan et al. 2014). Al igual que en otras patologías, el deterioro de la FEVI puede detectarse una vez se ha establecido el daño celular. Por este motivo se han multiplicado las publicaciones referentes a la detección de daño miocárdico subclínico mediante deformación miocárdica. En estos trabajos se ha reportado que la disminución de los valores de strain longitudinal siempre precede al descenso de la FEVI, y en otros casos es la única evidencia de disfunción sistólica. En promedio la magnitud del descenso de strain longitudinal se sitúa entre el $10 \%$ y $20 \%$. Negishi et.al. (2013) encontraron que un descenso del $11 \%$ del valor de GLS respecto al basal a los 6 meses postratamiento fue el principal predictor de cardiotoxicidad a los 12 meses, con una sensibilidad del $65 \%$ y especificidad del $94 \%$. Finalmente concluyeron que, aplicando un intervalo de confianza de $95 \%$, cambios $<8 \%$ de GLS no son clínicamente relevantes, mientras que los pacientes con descenso $>15 \%$ de GLS respecto al basal tienen altas probabilidades de presentar cardiotoxicidad. Se considera que la mejor estrategia es la del cambio de GLS respecto su valor basal, algunos estudios han intentado definir valores absolutos de GLS en aquellos pacientes sin estudio previo, sin embargo, no se han conseguido resultados fiables.

El documento de consenso de la Sociedad Europea de Cardiología (Plana et al. 2014) recomienda que tras detectarse un descenso $>15 \%$ de GLS el paciente sea referido para valoración cardiológica para que se discuta acerca del beneficio de continuar con el tratamiento antineoplásico o bien para iniciar medicamentos cardioprotectores.

Miocardiopatía hipertrófica.- Los mismos beneficios citados previamente aplican para la utilización de la deformación miocárdica en la miocardiopatía hipertrófica. La FEVI puede encontrarse normal o en rango superior debido a la reducción del tamaño de la cavidad ventricular y a que la deformación radial está incrementada para compensar la reducción de la deformación longitudinal (Cardim et al. 2015). Un valor inferior a $4 \mathrm{~cm} / \mathrm{s}$ de velocidad sistólica en el anillo lateral mitral, medido por DTI, se ha asociado a peor pronóstico clínico. De la misma manera valores regionales de strain longitudinal $>-10 \%$ en los segmentos septales se han relacionado con mayor susceptibilidad de arritmias ventriculares. El strain circunferencial ha dado resultados contradictorios, ya que puede encontrarse disminuido como consecuencia de una afectación de toda la pared miocárdica, o bien aumentado como mecanismo compensador del deterioro de la deformación longitudinal. Adicionalmente permite diferenciar entre hipertrofia patológica e hipertrofia fisiológica como la que presenta el corazón del atleta, el cual tendrá valores normales de GLS.

Amiloidosis.- El patrón de afectación producido por esta enfermedad puede ser difícil de diferenciar de otros patrones de hipertrofia. El uso de strain permite observa una afectación de todas las capas de la pared miocárdica, ya que todos los parámetros de deformación se encuentras reducidos (longitudinal, circunferencial y radial). Además, se ha observado una relativa preservación de los valores de strain longitudinal en los segmentos apicales, generando un gradiente apical/basal $>2,1$ (Koyama et al. 2015).

Ventrículo derecho.- La valoración del VD representa una dificultad debido a su forma y a la calidad de imagen obtenida. El estudio del strain longitudinal de la pared libre ha dado resultados alentadores en distintos escenarios como: cardiopatías congénitas, postquirúrgico de reparaciones de tetralogía de Fallot, tromboembolismo pulmonar, hipertensión pulmonar primaria y displasia arritmogénica del VD (Claus et al. 2015). No existen valores de referencia en las guías de cuantificación (Lang et al. 2015).

Aurícula izquierda.- Se considera que se encuentra aún en fase de herramienta de investigación, pero ya existen trabajos que demuestran su potencial utilidad para la medición de la función auricular y de las presiones de llenado (Claus et al. 2015).

\section{ECOCARDIOGRAFIA TRIDIMENSIONAL}

Es evidente pensar que la mejor manera de valorar una estructura tridimensional como el corazón, es precisamente, un método de imagen tridimensional; sin embargo, el desarrollo tecnológico necesario se ha alcanzado en los últimos 10-15 años aproximadamente. La llegada de los nuevos transductores generadores de matriz de muestreo completo (full sampled matrix-array) ha requerido un gran avance tanto en hardware como en software, ya que estos se componen de más de 3000 elementos piezoeléctricos de distintas frecuencias (Lang et al. 2012).

Aun así, en la actualidad existen limitaciones respecto a esta herramienta y se puede decir que sus principales ventajas se encuentran en (1) la valo- 
ración de volúmenes y masa del VI, (2) valoración de asimetrías regionales de la contractilidad y asincronía, (3) valoración anatómica/estructural de las válvulas cardíacas, (4) evaluación de insuficiencias valvulares y cortocircuitos y (5) ecocardiografía de estrés (Mor-Avi et al. 2012).

Adquisición de Imágenes.- Existen varias modalidades de adquisición:

- Tiempo real (Live 3D).- Se obtiene un volumen parcial de tamaño limitado (grosor y profundidad) que permitan trabajar con una mayor resolución temporal. No se afecta por la presencia de arritmias o movimiento del paciente. Se utiliza para la guía de procedimientos intervencionistas. Se puede añadir Doppler color.

- Zoom 3D.- Se obtiene un volumen de datos de una zona concreta del corazón. Cuando se adquieren varios volúmenes parciales aumenta la resolución espacial y temporal permitiendo una mayor definición anatómica; sin embargo, también aumenta la probabilidad de tener artefacto de emparejamiento o stitching, el cual se produce al juntar las imágenes obtenidas en cada latido; esto es más relevante en pacientes con arritmias o con cambios rápidos de contractilidad como en el ecocardiograma de estrés (Yang et al. 2008).

- Volumen completo.- Se obtiene una pirámide de datos de mayor tamaño que permite analizar una estructura completa. Requiere excelente trazado de ECG y apnea. También será susceptible de artefacto de emparejamiento, pero, además, mientras más latidos se empleen para la obtención de la imagen, mayor será la resolución espacial y temporal. En esta modalidad se puede añadir Doppler color para realizar el análisis de flujos, siempre que se asegure una alta resolución temporal.

Procesamiento.- Una vez se han adquirido los datos es necesario realizar varios pasos para obtener y optimizar la imagen requerida. El primer paso es el cropping o corte, al tener un modelo tridimensional es necesario "exponer" la estructura de interés y desde la perspectiva deseada. Así por ejemplo para visualizar el septo interventricular, es necesario cor-

A
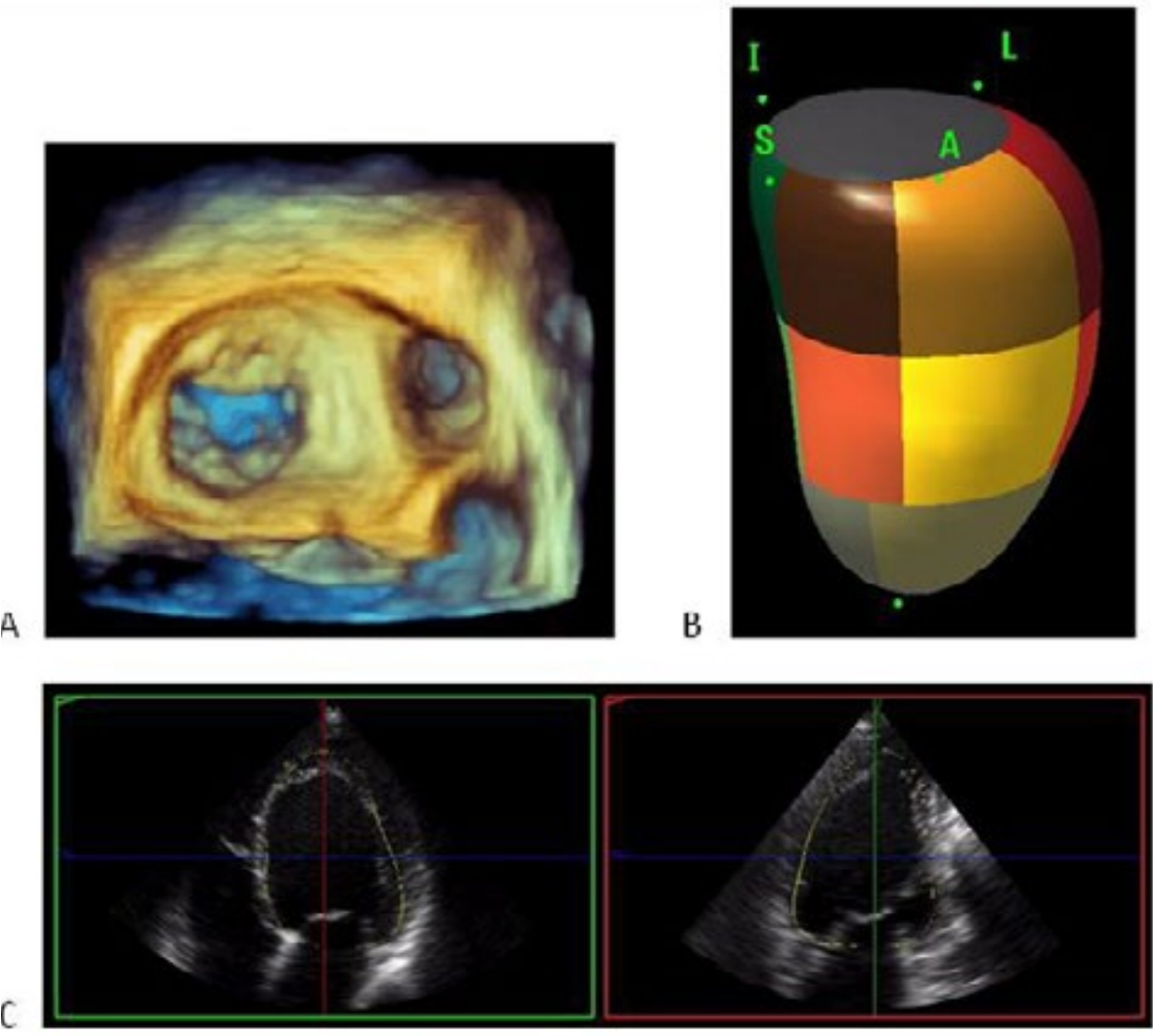

Figura 3. Formatos de representación de imágenes 3D. A: representación de volumen; B: representación de superficie (en este caso del ventrículo izquierdo con sus caras Anterior, Inferior, Septal y Lateral); C: cortes en 2D. 
tar la pared libre del VD o del VI para poder acceder. Esta parte del procesamiento puede realizarse durante o después de la adquisición de los datos en el paciente. A continuación, y según la indicación clínica del estudio, se selecciona el formato de visualización. Existen 3 tipos básicos: representación de volumen (volume rendering), representación de superficie (surface rendering) y cortes tomográfi$\cos 2$ D (Lang et al. 2012) (Figura 3).

Doppler color.- Posteriormente se puede añadir Doppler color para obtener información de flujos y función valvular. En este aspecto la imagen adquirida mediante ecocardiografía transesofágica (ETE) es superior a la ecografía transtorácica (ETT). De forma similar, la adquisición de volúmenes parciales obtiene mayor resolución temporal con la limitación de los artefactos de stitching; puede ser que el método de volumen completo no ofrezca la resolución temporal necesaria (Lang et al. 2012) (Figura 4).
Protocolo de estudio.- En la actualidad de la práctica clínica en muy pocas ocasiones se realiza un estudio tridimensional de todas las estructuras cardíacas, lo habitual es realizar el estudio 2D (ETT/ ETE) y posteriormente enfocar el examen 3D a la estructura de interés.

\section{Aplicaciones}

Ventrículo izquierdo: cuantificación de volúmenes y función sistólica.- El diagnóstico y pronóstico de la gran mayoría de cardiopatías se basan en la cuantificación del tamaño y función del VI. La ecocardiografía 2D tiene limitaciones como la utilización de fórmulas geométricas que no siempre coinciden con la morfología de la cavidad o el acortamiento apical del VI o foreshortening. Por este motivo es posible que la valoración del VI sea la aplicación del ETT 3D que más pueda trasladarse a la práctica clínica del día a día (Marwick 2012). Para la medición de volúmenes se puede optar entre

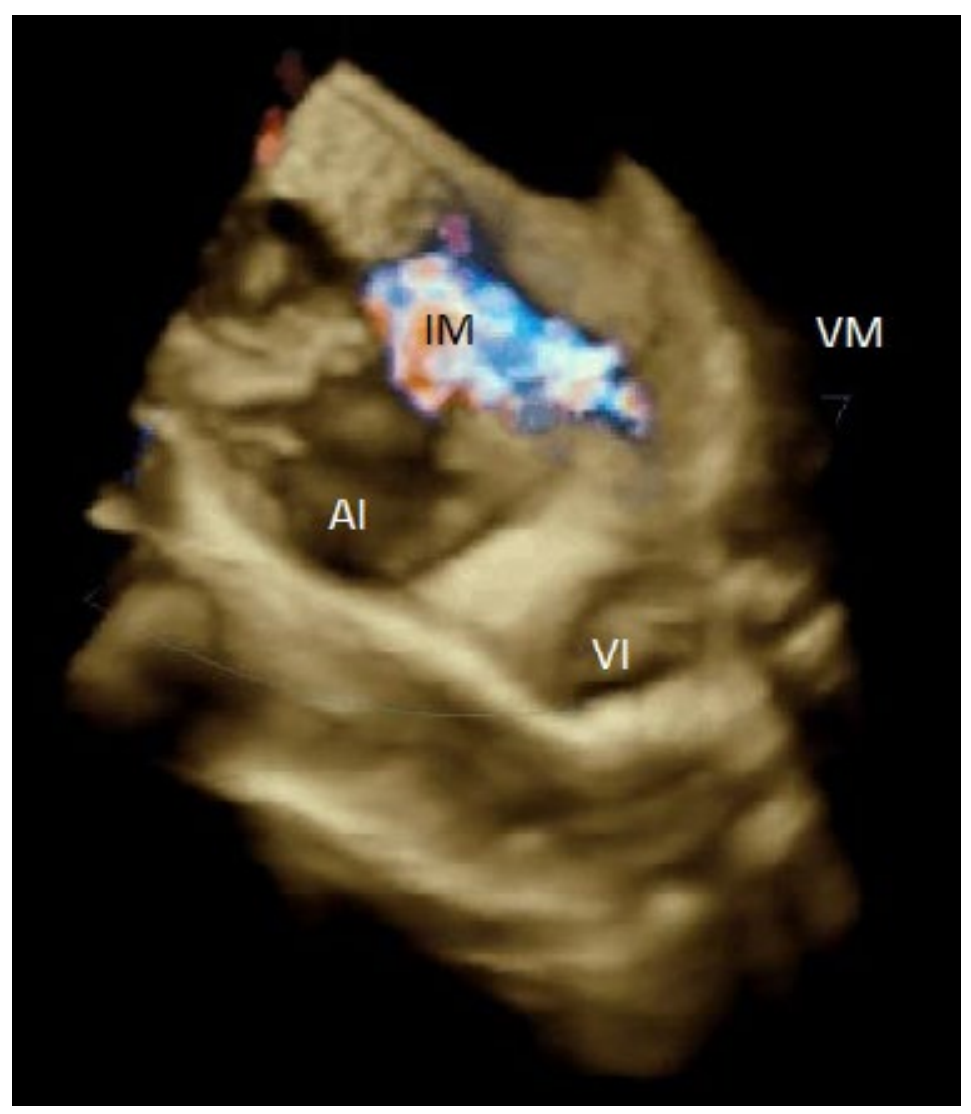

Figura 4. Imagen de ETT 3D con Doppler color. Jet de insuficiencia mitral (IM) visto desde la aurícula izquierda (AI) en ETE3D, se muestra el volumen tras el proceso de cropping necesario para ver las estructuras de interés. VI: ventrículo izquierdo, VM: válvula mitral. 
dos aproximaciones: el uso del transductor 3D para la selección de 2 planos verdaderamente ortogonales (evitando el foreshortening) con la posterior aplicación del método biplano convencional o el cálculo directo del volumen en un set de datos 3D completo (Figura 5).

Cualquiera que sea la aproximación escogida se ha
Estas recomendaciones se basan principalmente en el estudio de Chahal et.al., que realizaron ETT 3D a 978 personas sanas en el Reino Unido, en una población que incluía sujetos blancos e hindúes entre 35 y 75 años. Se obtuvieron imágenes de calidad suficiente para el análisis en el $89 \%$. Sus resultados mostraron que el ETT 2D infraestima los volúmenes del VI, pero sin diferir en FEVI. De igual

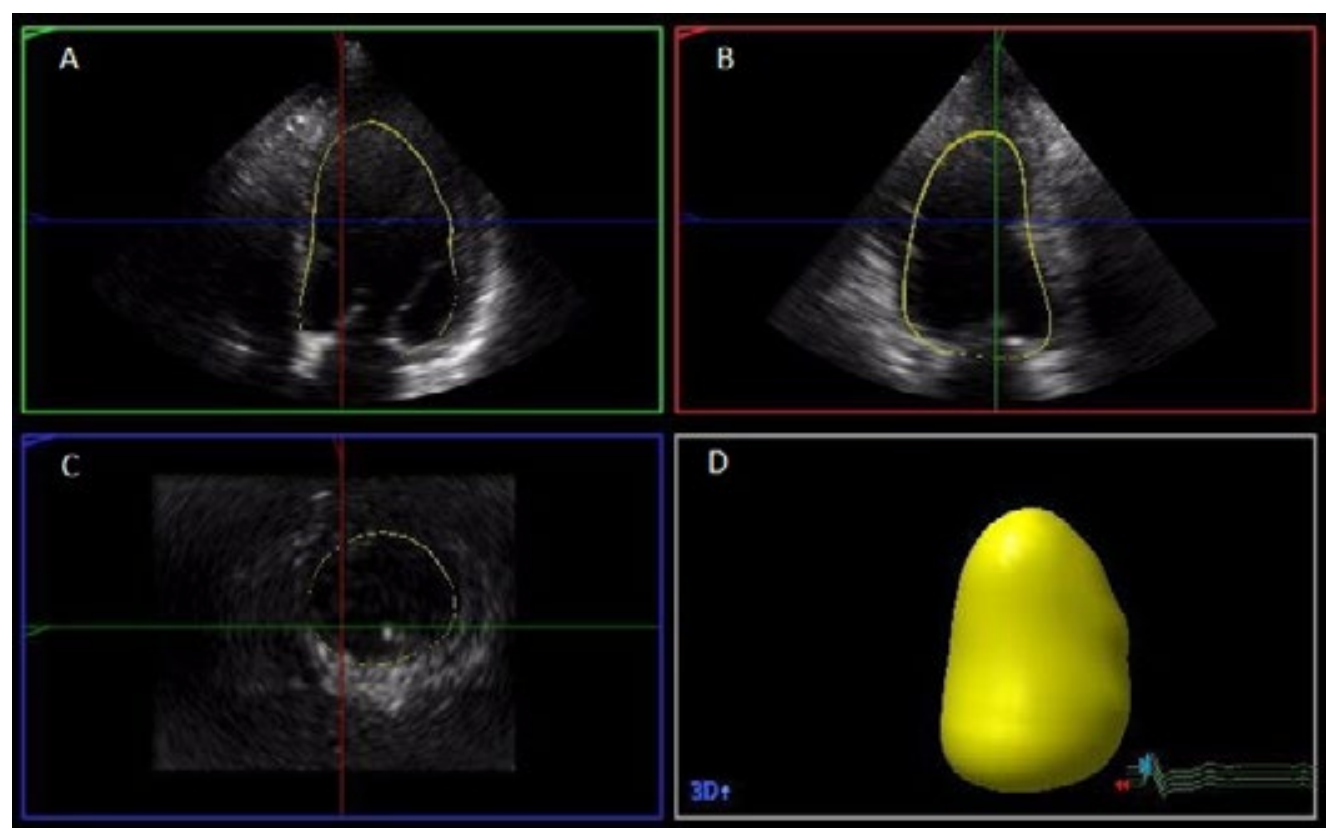

Figura 5. Cuantificación del ventrículo izquierdo mediante ETT 3D. En los cuadrantes A, B y C se observa la identificación automática del endocardio en los planos apical de 4 cavidades, 2 cavidades y eje corto, respectivamente. En el cuadrante D se observa la representación de superficie..

demostrado que los valores obtenidos por ETT 3D son más reproducibles, lo que facilita el seguimiento clínico de los pacientes, así como su respuesta al tratamiento. De igual manera se ha visto que tienen mayor concordancia que el ETT 2D, con respecto al patrón de oro de la resonancia magnética cardiaca (RMC), aunque con infraestimación de las cavidades. Adicionalmente, al compararlos con el ETT $2 \mathrm{D}$, los cálculos tridimensionales obtienen valores mayores (Lang et al. 2015).

Hasta el año anterior no se contaba con valores de referencia estandarizados por las guías de práctica clínica. El documento conjunto de las sociedades europeas y americanas sobre la cuantificación de cavidades (Lang et al. 2015) recomienda los siguientes puntos de corte para los valores indexados: volumen telediastólico en hombres $74 \mathrm{~mL} / \mathrm{m} 2$ y en mujeres $61 \mathrm{~mL} / \mathrm{m} 2$, volumen telesistólico en hombres $32 \mathrm{~mL} / \mathrm{m} 2$ y en mujeres $28 \mathrm{~mL} / \mathrm{m} 2$. manera se evidenció la influencia de la etnia en los rangos de normalidad (Chahal et al. 2012).

En lo que respecta a la valoración de la FEVI, las guías de cuantificación de cavidades dan el mismo valor a las mediciones por $2 \mathrm{D}$ que por $3 \mathrm{D}$, con los mismos rangos (Lang et al. 2015).

Ventrículo izquierdo: masa del ventrículo izquierdo.- El ETT 3D es la única técnica que mide directamente el volumen del miocardio, ya que los métodos lineales o de 2D utilizan fórmulas geométricas. Esto es más relevante en pacientes con hipertrofia septal asimétrica, ya que puede llevar a supra o infraestimaciones; en estos casos el ETT 3D representa una clara ventaja. Sin embargo, en las guías de cuantificación (Lang et al. 2015) no se recomienda el uso sistemático del ETT 3D debido a que los estudios que han explorado los valores normales en la población aún son limitados. 
Ventrículo izquierdo: Asincronía.- Se base en la comparación del mínimo volumen regional (máxima contracción) respecto al tiempo; en un ventrículo normal todos los segmentos alcanzan el volumen mínimo a la vez, sin embargo, ante la presencia de asincronía existe dispersión en el tiempo y se puede calcular ese retraso. Estos datos se presentan en curvas y en esquemas bull's eye, además permiten crear un índice de asincronía sistólica (systolic dyssynchrony index - SDI) en función de la desviación estándar del retraso (Lang et al. 2012). Existen pequeños estudios que han demostrado cierto beneficio pronóstico en pacientes que han sido sometidos a terapia de resincronización cardíaca.

Ecocardiografía de estrés.- Existen muchos datos publicados de la utilidad del ETT 3D en pruebas de estrés con ejercicio o fármacos, con valores adecuados de sensibilidad y especificidad. Las principales ventajas son la mejor visualización del ápex, la rapidez con las que se adquieren las imágenes en el pico de estrés y la capacidad de analizar los segmentos desde distintos planos a partir del mismo set de imágenes. El principal problema es la menor resolución espacial. La capacidad del transductor de registrar 2 o 3 planos de forma simultánea es lo que reduce los tiempos de adquisición. De forma alternativa se puede adquirir el volumen completo de datos de 3D para posteriormente procesarlos y comparar los segmentos en el plano necesario. El análisis de la contractilidad segmentario se realiza desplegando las imágenes en los planos convencionales $2 \mathrm{D}$ o bien de cortes tomográficos de eje corto, durante las distintas fases.

Válvula mitral.- La valoración de la compleja anatomía y función mitral se realiza con imágenes adquiridas en el modo zoom, lo que permite utilizar la máxima resolución temporal y espacial (Quader et al. 2014, Buck y Plitch 2015). El mayor avance respecto a las técnicas $2 \mathrm{D}$, es la posibilidad de observar la válvula desde una perspectiva frontal, bien desde el VI o desde la aurícula izquierda (AI). Esta última es la denominada "vista de cirujano" ya que es la misma que se tiene cuando durante la cirugía se abre la AI.

Adicionalmente con el proceso de cropping se pueden obtener cualquier plano de la válvula mitral, convencional o no convencional, los cuales pueden ser necesarios para la valoración del aparato subvalvular (cuerdas tendinosas), masas o prolapso de festones (Figura 6).

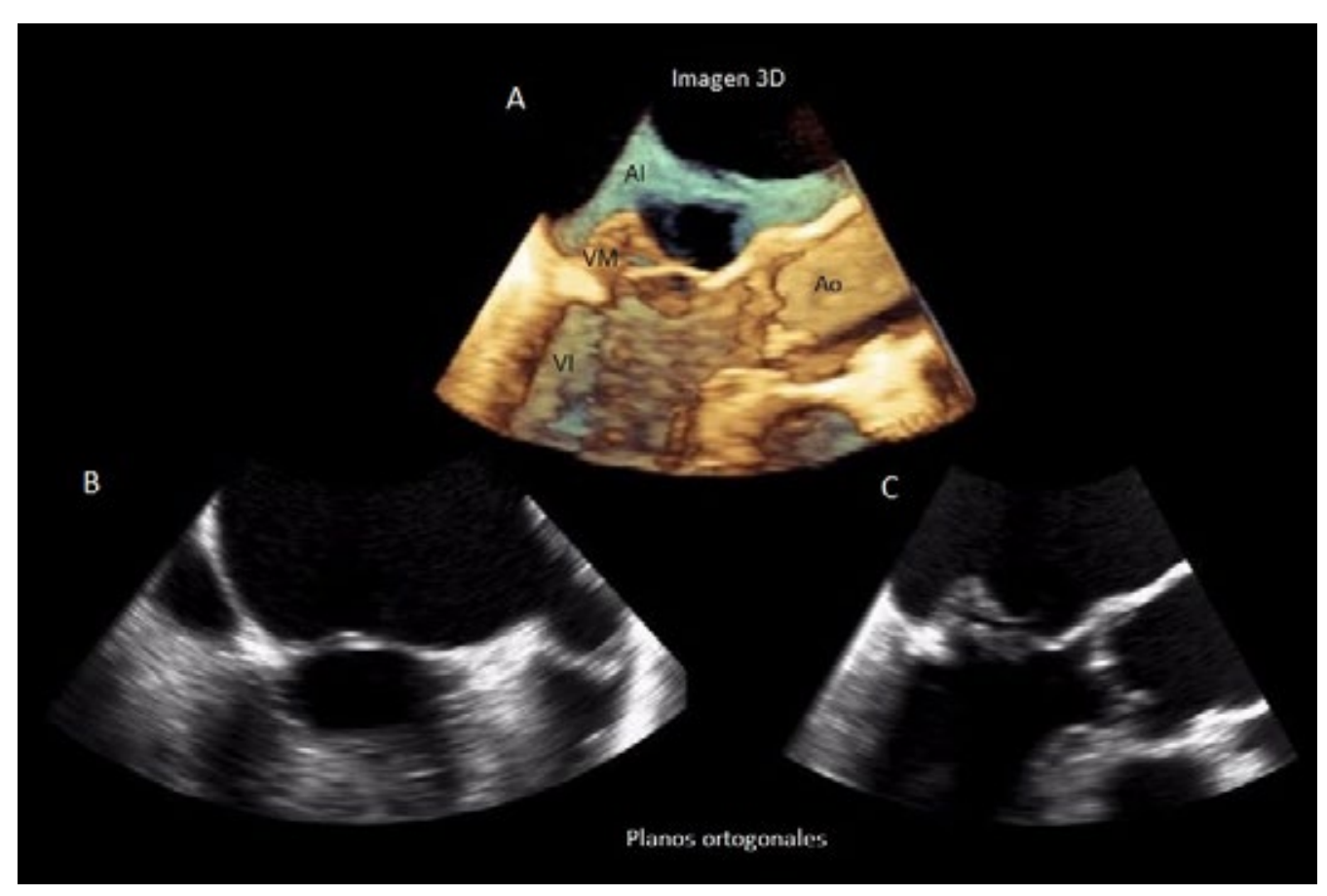

Figura 6. Imagen de la válvula mitral. Imagen de la válvula mitral (VM) mediante ETE 3D. A: se muestra la reconstrucción tridimensional tras realizar cropping a nivel del tracto de salida del ventrículo izquierdo. B y C: se muestran los planos 2D ortogonales en un paciente con prolapso del velo posterior. Ao: Aorta, AI: aurñicula izquierda, VI: ventrículo izquierdo. 
La valoración del anillo mitral es única de la ecocardiografía 3D, ya que su forma hiperbólica impide que sea visualizada por medio de $2 \mathrm{D}$. La reconstrucción del anillo ofrece datos de su tamaño (diámetro), forma y orientación exacta. Esta información facilita la valoración prequirúrgica, incluyendo la factibilidad de la reparación y la elección del tipo y tamaño de anillo de valvuloplastia (Figura 7).

Las aplicaciones de esta técnica en la patología mitral son muchas, incluyendo la valoración del grado y extensión de afectación estructural: enfermedad mixomatosa, degenerativa, masas, vegetaciones o alteraciones congénitas como clefts/hendiduras. Las prótesis valvulares se visualizan mejor con ETE 3D, lo que mejora el diagnóstico de leaks o fugas paravalvulares.

En lo que respecta a la cuantificación de la estenosis mitral, las imágenes 3D posibilitan obtener el plano más apical de la apertura valvular, midiendo de forma precisa el área valvular mitral, y superando a la planimetría 2D que sobrestima este valor.
De igual manera la medición de la vena contracta, mediante ETT/ETE 3D, en casos de regurgitación mitral ha supuesto un avance significativo en el objetivo de cuantificar la severidad de esta entidad, ya que se ha comprobado que no tiene forma circular, sino elipsoide, especialmente en IM funcional. De igual manera se puede medir el área PISA, la cual en muchos casos no es hemisférica.

Válvula aórtica.- Las técnicas 3D permite la visualización de la válvula aórtica desde su cara aórtica o ventricular, así como a través de cualquier plano de corte. Para la identificación de masas/vegetaciones la vista desde el VI es de mayor utilidad, mientras que para el estudio morfológico y estructural se prefiere el plano obtenido desde la aorta (Shiota 2014). Se ha comprobado que el ETT 2D infraestima el área del TSVI, ya que se calcula presumiendo una estructura circular. El ETT/ETE 3D proporcionan una visión más real. De lo anterior se deduce que el cálculo del área valvular aórtica, derivada de estos valores, es más exacto, mejorando así la evaluación de la severidad de la valvulopatía (Jánosi et al. 2014).

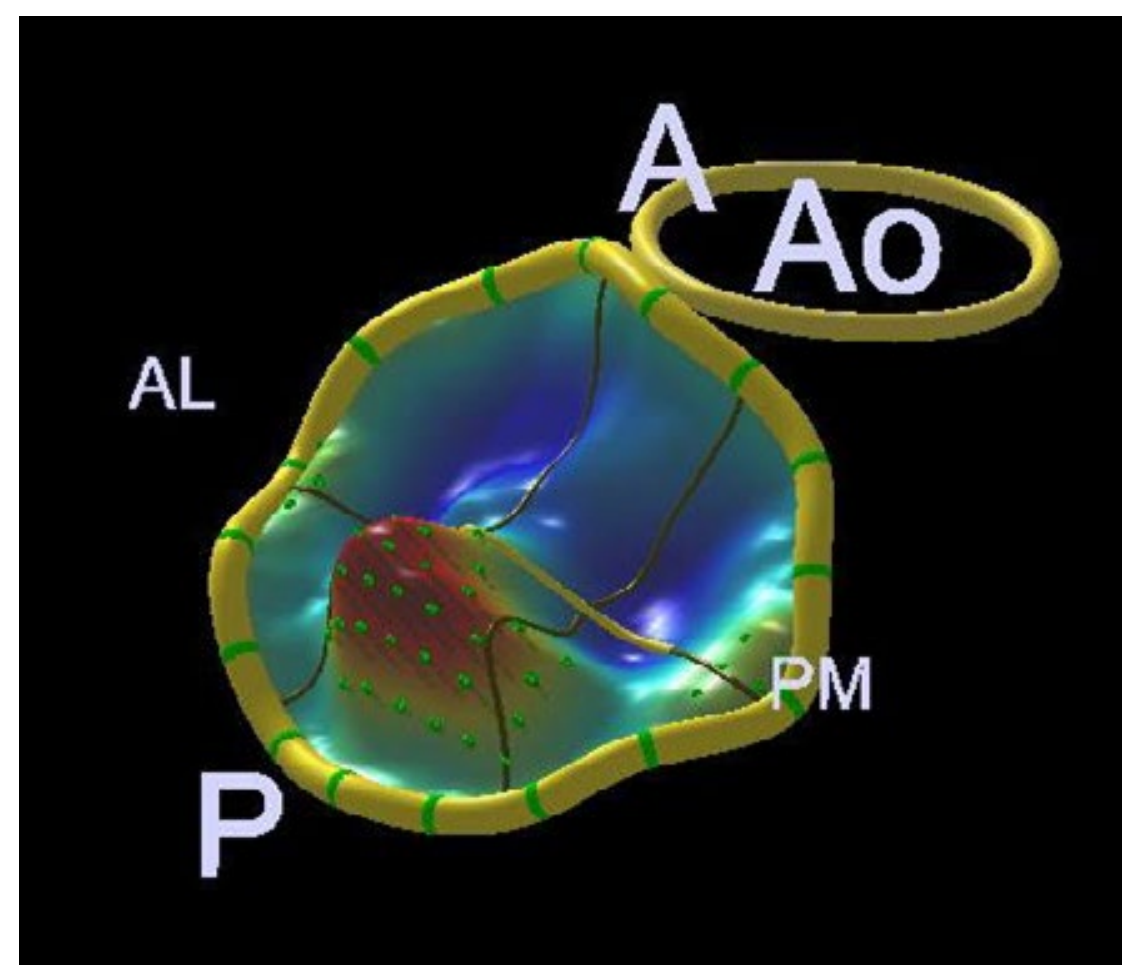

Figura 7. Reconstrucción 3D del anillo mitral. Reconstrucción tridimensional del anillo mitral en la misma paciente que la Figura 6. Se observa prolapso del velo posterior a nivel del festón P2. Además del análisis visual, el software proporciona valores de diámetro, angulación y cuantificación del volumen prolapsado (entre otros). A: anterior, AL: comisura mitral anterolateral, Ao: aorta, P: posterior, PM: comisura mitral posteromedial. 
En la actualidad el implante percutáneo de prótesis aórticas se ha consolidado como técnica de elección para el tratamiento de pacientes con alto riesgo quirúrgico o inoperables. En estos casos se requiere determinar las dimensiones del anillo valvular y la raíz aórtica con el objetivo de seleccionar el modelo y tamaño del dispositivo. Otra medida requerida es la distancia desde el anillo aórtico a la salida de las coronarias, parámetro de seguridad del procedimiento. De igual manera se debe evaluar la severidad y localización de la calcificación en las cúspides, que es un dato que se relaciona con el éxito del procedimiento. Aunque es factible realizar esta valoración mediante ETE3D, en la actualidad la técnica de elección es el TC cardíaco, ya que varios estudios demuestran que presenta una infraestimación del anillo de hasta el $10 \%$ ( $\mathrm{Ng}$ et al. 2010). Por último, las mismas ventajas señaladas para el estudio de la IM pueden aplicar para la regurgitación aórtica.
Ventrículo derecho.- La anatomía del VD es compleja y constituye el factor limitante para su valoración. La imagen 3D ha permitido desarrollar software específico que mediante la detección automática del borde endocárdico calcula la fracción de eyección del VD (FEVD) (Kossaify 2015). Las guías de cuantificación de cavidades (Lang et al. 2015) recomiendan que su uso sea limitado a centros con experiencia y proponen un valor de corte de $45 \%$ como límite inferior de la normalidad.

Cardiopatía estructural.- Los planos adquiridos permiten una visualización única de patologías como comunicación interauricular, comunicación interventricular o complicaciones mecánicas del infarto de miocardio como la rotura de músculo papilar, (Figuras 8 y 9).

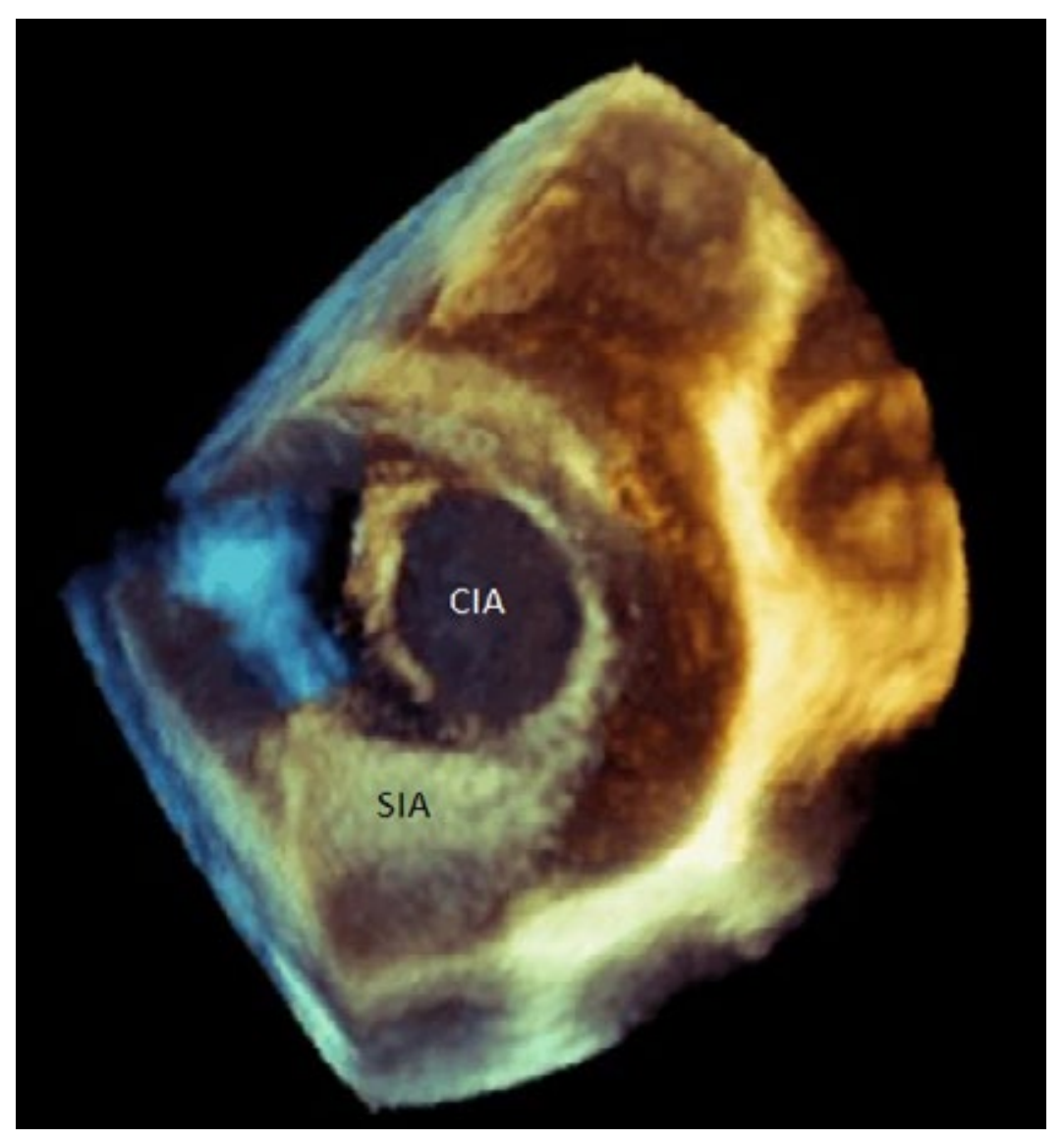

Figura 8. Imagen 3D de CIA Reconstrucción tridimensional del anillo mitral en la misma paciente que la Figura 6. Se observa prolapso del velo posterior a nivel del festón P2. Además del análisis visual, el software proporciona valores de diámetro, angulación y cuantificación del volumen prolapsado (entre otros). A: anterior, AL: comisura mitral anterolateral, Ao: aorta, P: posterior, PM: comisura mitral posteromedial. 


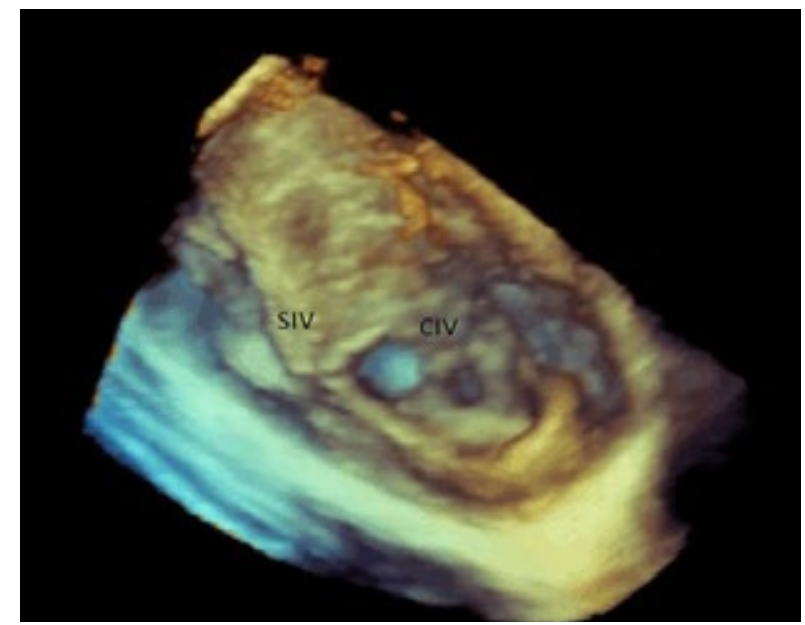

Figura 9. Imagen 3D de CIV. Imagen de ETE 3D. Se observa CIV (Comunicación Interventricular) desde el ventrículo izquierdo. SIV: septo interventricular.

Guía en intervencionismo cardíaco.- En los últimos años se ha producido un gran aumento en los procedimientos de intervencionismo estructural que requieren de la guía de la imagen, entre ellos se encuentran: cierre de orejuela izquierda, cierre de defectos del septo interauricular, reparación de válvula mitral (MitraClip ${ }^{\circledR}$ ), cierre de leaks paravalvulares y punción trans-septal. Adicionalmente existe otros procedimientos como el implante de prótesis valvulares aórticas (TAVI) o valvuloplastias que pueden necesitar apoyo en casos seleccionados. Y por si fuera poco están en desarrollo nuevas técnicas para abordar las válvulas tricúspide y pulmonar.

Cada técnica requiere de distintos planos o perspectivas a lo largo del procedimiento, por lo cual la descripción detallada de cada uno de ellos queda fuera del objetivo de este curso. Existen documentos de revisión (Faletra et al. 2014) que resumen la utilidad de la imagen 3D para cada intervención (Figura 10).

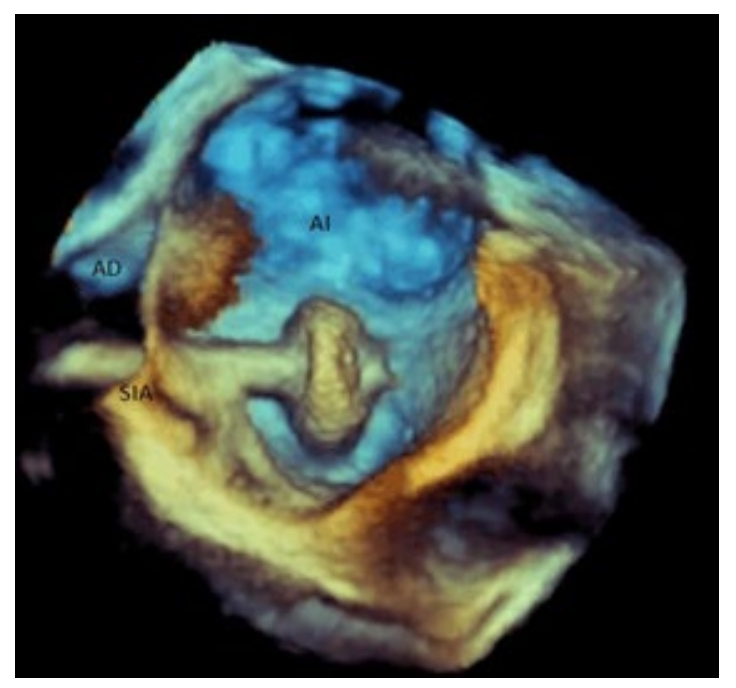

Figura 10. Implante de dispositivo de cierre de CIA. Imagen de ETE 3D. Se observa como el dispositivo ha atravesado el septo interauricular (SIA) desde la aurícula derecha (AD) y se encuentra en la aurícula izquierda (AI). 


\section{CONCLUSIÓN}

El constante desarrollo tecnológico ha permitido incorporar estas técnicas ecocardiográficas a la práctica diaria. Su correcto uso se basa en el entendimiento de sus principios y en un adecuado protocolo de adquisición y análisis. La utilidad y repercusiones clínicas han quedado ampliamente demostradas en algunas patologías, mientras que en otras es necesario ser prudente e integrar estos nuevos datos en un contexto más amplio durante el proceso de toma de decisiones. Ambas técnicas representan un campo para investigación, sobre todo, en la búsqueda del impacto de estas determinaciones en términos de morbilidad y mortalidad.

\section{REFERENCIAS BIBLIOGRÁFICAS}

Asanuma T, Nakatani S. 2015. Myocardial ischaemia and post-systolic shortening. Heart. 101(7):509-516.

Buck T, Plicht B. (2015). Real-Time Three-Dimensional Echocardiographic Assessment of Severity of Mitral Regurgitation Using Proximal Isovelocity Surface Area and Vena Contracta Area Method. Lessons We Learned and Clinical Implications. Curr Cardiovasc Imaging Rep. 8(10):38.

Cardim N, Galderisi M, Edvardsen T, Plein S, Popescu BA, D'Andrea A, Bruder O, Cosyns B, Davin L, Donal E, et al. (2015). Role of multimodality cardiac imaging in the management of patients with hypertrophic cardiomyopathy : an expert consensus of the European Association of Cardiovascular Imaging Endorsed by the Saudi Heart Association. Eur Heart J Cardiovasc Imaging. 16(3):280.

Chahal N, Lim T, Jain P, Chambers J, Kooner J, Senior R. (2012). Population-Based Reference Values for 3D Echocardiographic LV Volumes and Ejection Fraction. JACC Cardiovasc Imaging. 5(12):1191-1197.

Claus P, Omar AMS, Pedrizzetti G, Sengupta PP, Nagel E. (2015). Tissue Tracking Technology for Assessing Cardiac MechanicsPrinciples, Normal Values, and Clinical Applications. JACC Cardiovasc Imaging. 8(12):1444-60.

Duncan AE, Alfirevic A, Sessler DI, Popovic ZB,
Thomas JD. (2014). Perioperative Assessment of Myocardial Deformation. Anesth Analg. 118(3):525-44.

Faletra FF, Pedrazzini G, Pasotti E, Muzzarelli S, Dequarti MC, Murzilli R, Schlossbauer SA, Petrova I, Moccetti T. (2014). 3D TEE During Catheter-Based Interventions. JACC Cardiovasc Imaging. 7(3):292-308.

Farsalinos KE, Daraban AM, Ünlü S, Thomas JD, Badano LP, Voigt J-U. (2015). Head-toHead Comparison of Global Longitudinal Strain Measurements among Nine Different Vendors The EACVI/ASE Inter-Vendor Comparison Study. J Am Soc Echocardiogr. 28(10):1171-1181.

Galli E, Lancellotti P, Sengupta PP, Donal E. (2014). LV mechanics in mitral and aortic valve diseases: value of functional assessment beyond ejection fraction. JACC Cardiovase Imaging. 7(11):1151-1166.

Jánosi RA, Plicht B, Kahlert P, Eißmann M, Wendt D, Jakob H, Erbel R, Buck T. (2014). Quantitative Analysis of Aortic Valve Stenosis and Aortic Root Dimensions by Three-Dimensional Echocardiography in Patients Scheduled for Transcutaneous Aortic Valve Implantation. Curr Cardiovasc Imaging Rep. 7:9296.

Kalam K, Otahal P, Marwick T. (2014). Prognostic implications of global LV dysfunction: a systematic review and meta-analysis of global longitudinal strain and ejection fraction. Heart. 100(21):1673-1680.

Kossaify A. (2015). Echocardiographic Assessment of the Right Ventricle, from the Conventional Approach to Speckle Tracking and Three-Dimensional Imaging, and Insights into the "Right Way" to Explore the Forgotten Chamber. Clinical Medicine Insights Cardiology 9:65-75.

Koyama J, Ikeda S, Ikeda U. (2015). Echocardiographic Assessment of the Cardiac Amyloidoses. Circ. J. 79(4):721-734.

Kraigher-krainer E, Shah AM, Gupta DK, Santos A, Claggett B, Pieske B, Zile MR, Voors AA, Lefkowitz MP, Packer M, et al. (2014). Impaired Systolic Function by Strain Imaging 
in Heart Failure With Preserved Ejection Fraction. J Am Coll Cardiol. 63(5):447456.

Lafitte S, Perlant M, Reant P, Serri K, Douard H, DeMaria A, Roudaut R. (2009). Impact of impaired myocardial deformations on exercise tolerance and prognosis in patients with asymptomatic aortic stenosis. Eur Heart J Cardiovasc Imaging. 10(3):414-419.

Lancellotti P, Cosyns B, Zacharakis D, Attena E, Van Camp G, Gach O, Radermecker M, Piérard LA. (2008). Importance of Left Ventricular Longitudinal Function and Functional Reserve in Patients With Degenerative Mitral Regurgitation: Assessment by Two-Dimensional Speckle Tracking. J Am Soc Echocardiogr. 21(12):1331-1336.

Lang RM, Badano LP, Tsang W, Adams DH, Agricola E, Buck T, Faletra FF, Franke A, Hung J, Pérez de Isla L, et al. (2012). EAE/ASE Recommendations for Image Acquisition and Display Using Three-Dimensional Echocardiography. J Am Soc Echocardiogr. 25(1):3-46.

Lang RM, Badano LP, Mor-Avi V, Afilalo J, Armstrong A, Ernande L, Flachskampf FA, Foster E, Goldstein SA, Kuznetsova T, et al. (2015). Recommendations for Cardiac Chamber Quantification by Echocardiography in Adults: An Update from the American Society of Echocardiography and the European Association of Cardiovascular Imaging. J Am Soc Echocardiogr. 28(1):1-39.

Mada RO, Duchenne J, Voigt J-U. (2014). Tissue Doppler, strain and strain rate in ischemic heart disease "how I do it". Cardiovasc Ultrasound 12(1):38.

Magne J, Mahjoub H, Dulgheru R, Pibarot P, Pierard LA, Lancellotti P. (2014). Left ventricular contractile reserve in asymptomatic primary mitral regurgitation. Eur Heart J. 35(24):1608-1616.

Marwick T. (2012). Application of 3D echocardiography to everyday practice: Development of normal ranges is step 1. JACC Cardiovasc Imaging 5(12):1198-1200.
Marwick T. (2012). Strain and Strain Rate Imaging Advanced Echocardiographic Approaches. En: Gillam L y Otto C (eds) Advanced Approaches in Echocardiography:84-102. Elsevier Inc. Philadelphia.

Mor-Avi V, Lang RM, Badano LP, Belohlavek M, Cardim N, Derumeaux G, Galderisi M, Marwick T, Nagueh SF, Sengupta PP, et al. (2011). Current and evolving echocardiographic techniques for the quantitative evaluation of cardiac mechanics: ASE/ EAE consensus statement on methodology and indications endorsed by the Japanese Society of Echocardiography. Eur J Echocardiogr. 12(3):167-205.

Motoki H, Borowski AG, Shrestha K, Troughton RW, Tang WHW, Thomas JD, Klein AL. (2012). Incremental prognostic value of assessing left ventricular myocardial mechanics in patients with chronic systolic heart failure. J Am Coll Cardiol. 60(20):20742081.

Nahum J, Bensaid A, Dussault C, Macron L, Clémence D, Bouhemad B, Monin J-L, Rande J-LD, Gueret P, Lim P. (2010). Impact of Longitudinal Myocardial Deformation on the Prognosis of Chronic Heart Failure Patients. Circ. Cardiovasc. Imaging. 3(3):249-256.

Negishi K, Negishi T, Hare JL, Haluska BA, Plana JC, Marwick T. (2013). Independent and Incremental Value of Deformation Indices for Prediction of Trastuzumab-Induced Cardiotoxicity. J. Am. Soc. Echocardiogr. 26(5):493-498.

Ng A, Delgado V, van der Kley F, Shanks M, van de Veire N, Bertini M, Nucifora G, van Bommel R, Tops L, de Weger A. (2009). Comparison of Aortic Root Dimensions and Geometries Before and After Transcatheter Aortic Valve Implantation by 2- And 3-Dimensional Transesophageal Echocardiography and Multislice Computed Tomography. Circ Cardiovasc Imaging. 3(1):94-102.

Opdahl A, Helle-Valle T, Skulstad H, Smiseth OA. (2015). Strain, Strain Rate, Torsion, and Twist: Echocardiographic Evaluation. Curr Cardiol Rep. 17(3):15. 
Plana JC, Galderisi M, Barac a., Ewer MS, Ky B, Scherrer-Crosbie M, Ganame J, Sebag I a., Agler D a., Badano LP, et al. (2014). Expert consensus for multimodality imaging evaluation of adult patients during and after cancer therapy: a report from the American Society of Echocardiography and the European Association of Cardiovascular Imaging. Eur Heart J Cardiovasc Imaging. 15(10):1063-1093.

Quader N, Rigolin VH. (2014). Two and three dimensional echocardiography for pre-operative assessment of mitral valve regurgitation. Cardiovasc. Ultrasound. 12(1):42.

Sengelov M, Jorgensen PG, Jensen JS, Bruun NE, Olsen FJ, Fritz-hansen T, Nochioka K, Biering-sørensen T. (2015). Global Longitudinal Strain Is a Superior Predictor of All-Cause Mortality in Heart Failure With Reduced Ejection Fraction. JACC Cardiovasc Imaging. 8(12):1351-1359.

Sengupta PP, Korinek J, Belohlavek M, Narula J, Vannan MA, Jahangir A, Khandheria BK. (2006). Left Ventricular Structure and Function. J Am Coll Cardiol. 48(10):19882001.

Shah AM, Claggett B, Sweitzer NK, Shah SJ, Anand IS, Liu L, Pitt B, Pfeffer MA, Solomon SD. (2015). Prognostic Importance of Impaired Systolic Function in Heart Failure With Preserved Ejection Fraction and the Impact of Spironolactone. Circulation. 132(5):402-414.

Shiota T. (2014). Role of modern 3D echocardiography in valvular heart disease. Korean J Intern Med. 29(6):685-702.

Stanton T, Leano R, Marwick T. (2009). Prediction of All-Cause Mortality From Global Longitudinal Speckle Strain: Comparison With Ejection Fraction and Wall Motion Scoring. Circ Cardiovasc Imaging. 2(5):356364.

Thavendiranathan P, Poulin F, Lim K-D, Plana JC, Woo A, Marwick T. (2014). Use of Myocardial Strain Imaging by Echocardiography for the Early Detection of Cardiotoxicity in Patients During and After Cancer Chemotherapy. J Am Coll Cardiol.
63(25):2751-2568.

Vahanian A, Alfieri O, Andreotti F, Antunes MJ, Barón-Esquivias $\mathrm{G}$, Baumgartner $\mathrm{H}$, Borger MA, Carrel TP, De Bonis M, Evangelista A, et al. (2012). Guidelines on the management of valvular heart disease (version 2012). Eur Heart J. 33(19):2451-2496.

Weidemann F, Herrmann S, Störk S, Niemann M, Frantz S, Lange V, Beer M, Gattenlöhner S, Voelker W, Ertl G, et al. (2009). Impact of Myocardial Fibrosis in Patients With Symptomatic Severe Aortic Stenosis. Circulation. $120(7): 577-584$.

Yang HS, Bansal RC, Mookadam F, Khandheria BK, Tajik a. J, Chandrasekaran K. (2008). Practical Guide for Three-Dimensional Transthoracic Echocardiography Using a Fully Sampled Matrix Array Transducer. J Am Soc Echocardiogr. 21(9):979-989 